\title{
A Study on the Performance of the Saffron Separator for Different Air Flows
}

\author{
Abbas Moghanizadeh ${ }^{1 *}$, Mehdi Neshat ${ }^{2}$ \\ ${ }^{1}$ Department of Mechanic, Shirvan Branch, Islamic Azad University, Shirvan, Iran \\ ${ }^{2}$ Department of Computer Engineering, Shirvan Branch, Islamic Azad University, Shirvan, Iran.
}

\section{A R T I C LE IN F O}

\section{Article history:}

Received 05 August 2014

Accepted 10 October 2014

Available online, ISSN: 2148-127X

\section{Keywords:}

Saffron

Stigma

Aerodynamic properties

Air flow speed

Anther

\section{A B S T R A C T}

Saffron, the dried stigmas of Crocus sativus, is extremely appreciated for its extraordinary color, taste and aroma. At the present time, nearly all the saffron harvest and post harvest processes are carried out manually. To increase the quality and development of economic role of saffron, it is essential to go beyond the traditional method of harvest of saffron. Considering that saffron components terminal velocities are different, a separator is planned and constructed to separate stigma from other parts of saffron flower. This separator is designed on the basis of aerodynamic and physical properties of saffron flower. The purpose of this study is to analyze the performance of a saffron separator for different air flows to increase the level of automation and efficiency of post-harvest operations. The results show that the maximum stigma separation happens when the air flow speed in outlet B is $3 \mathrm{~m} / \mathrm{s}$. finally, this data will be applied to find the optimum areas of outlet B and D, as two main parameters which have significant effect on the efficiency of saffron separator.

\footnotetext{
${ }^{*}$ Corresponding Author:

E-mail: abbas.moghanizadeh@ gmail.com
}

\section{Introduction}

\section{Saffron application}

Saffron, the desiccated stigmas of Crocus sativus, is highly appreciated for its peculiar color, flavor and aroma (Gracia et al., 2009). It is a spice which has been well known since antiquity and it (Crocus sativus) is one of the most expensive edible flowers of the world (Emadi, 2009). The Crocus genus includes approximately 80 species; however, it is known mainly for the cultivated species $C$. sativus, commonly called saffron Crocus sativus which is an autumn-flowering geophyte extensively grown in the Mediterranean basin, Middle East and Near East since the Late Bronze Age (Negbi, 1999). Moreover, it contains a carotenoid dye, crocin, which provides food a rich golden-yellow hue. These traits make saffron a much-sought ingredient in many foods worldwide. Saffron further has medicinal applications (Castillo et al., 2005), (Premkumar et al., 2006). The novel use of saffron in recent years has been associated with cancer cure (Abdullaev, 2004).

Saffron (Crocus sativus L.) is a perennial spice species of Iridaceae family which has been spread out in Mediterranean and west of Asia from 10 west to 80 east degrees of geographical longitude, as well as from 30 to 50 north degrees of geographical latitude and up to 1000 meters above sea level (Kafi et al. , 2002). The stigma, as the only economic part of flower has eatable and medicinal applications.

\section{Saffron properties}

Saffron flower includes three main parts: petal, stigma and anther which are shown in the figure 1 . The outstanding feature of the flower among the three-part is the brilliant red stigma, 25-30 mm long, which droops over the perianth segments (McGimpsey et al., 1997). A flower has several petals (P) namely at least three, which are separate from one another. The petals range from $30.50 \mathrm{~mm}$ to $46 \mathrm{~mm}$ in length with a mean of $38.28 \mathrm{~mm}$. Anther size is approximately $20.52 \mathrm{~mm}$. Each stigma is 23-39 mm in length with a mean of $30.8 \mathrm{~mm}$ and usually hangs between the petals of the open flowers. The average range of these properties for the three different parts of saffron flower is about 0.03 to $0.16 \mathrm{~g} / \mathrm{cm}^{3}$ for bulk density, 0.55 to $1.56 \mathrm{~g} / \mathrm{cm}^{3}$ for true density, and 85.2 to $95.5 \%$ for porosity (Emadi and Saiedirad, 2011). 


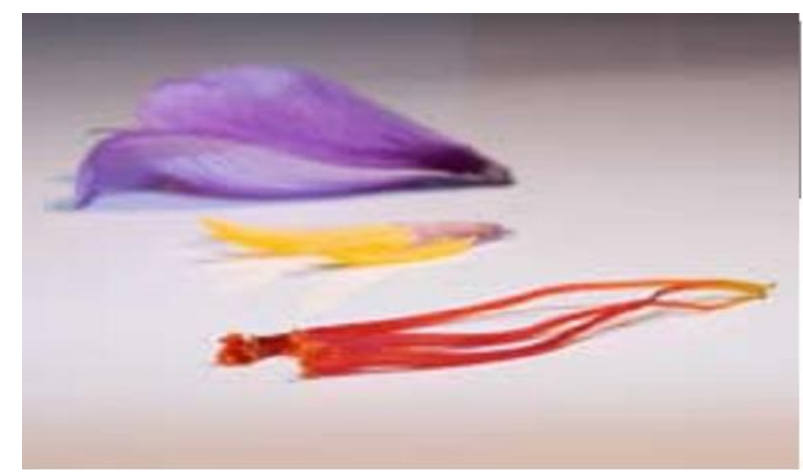

Figure 1 Parts of saffron flower

\section{Design of the saffron flower parts separating system}

Overview of the separating saffron flowers parts machine

The saffron harvesting begins when flowers start sprouting during mid or late October and lasts for a couple of weeks. A saffron farm needs manual and daily harvesting; moreover, flower harvesting is traditionally carried out by hand. The flower is cut at the lower part of its corolla and placed carefully in small baskets avoiding pressure. It is one of the most traditional procedures which have been followed identically throughout the centuries. It consists of removing the stigma from the rest of the flower. It reduces the quality of flower which has a significant effect on flower processing. However, the properties of saffron change within days after harvest since the properties of agricultural produce are moisture content dependent (Aydin, 2002); (Demir and Akinci, 2004); (Ozguven and Vursavus, 2005).

The whole operation takes about 5 second per flower which is mainly responsible for the high cost of saffron. There are 2170 flowers in each kilo of harvested fresh flower, and the processing of every 78 kilos of fresh flowers results in one kilo of dried saffron (Emadi, 2009), which implies nearly $230 \mathrm{hrs}$. of labors to peel the stigmas from other parts of saffron.

Nowadays, all the saffron operations are approximately accomplished manually. To attribute to the saffron development as a significant economic role, it is necessary to go beyond the traditional method of production. Several machines for saffron bulb planting have been developed (Mohammad, 2006). In addition, new machine for automated cutting of saffron flowers to obtain their stigmas has been developed. The key point of the invention is the use of a vision system to obtain the optimal cutting point using image analysis. A new machine has been patented and a prototype has been manufactured for experimentation and validation (Gracia et al., 2009). It is tried to separate saffron parts independently by the use of airflows which remove the other parts; therefore, three models of air separation which several structural differences at duct diameter, air speed and the separation surface are examined (Paschino and Gambella, 2008). The investigation result on terminal velocity measurement of three main parts of the flower revealed that the separation stigma from the other parts of flower is possible (Emadi and Saiedirad, 2011) since at the time of floating; the weight of particles is equal to the drag force (Mohsenin, 1986).
In the other research, shear strength and shear energy per unit area of saffron (Crocus sativus L.) stalk were determined as a function of bevel angle and shear velocity since they are important parameters to design and develop harvesting mechanisms (Hassan-Beygi et al., 2010). In a novel study, a mechanical system was designed to harvest Crocus sativus (saffron) flowers which collected the detached flower through a vacuum collector. The system was carried by the human operator on his back (Bertetto et al., 2010). A prototype for harvesting Crocus sativus (saffron) flowers was developed which had a simple design and was capable of performing the cutting procedure mechanically (Ruggiu and Bertetto, 2006).

Thus, it has been determined that developing a device which leads to the automation or semi-automation of Crocus sativus harvesting is a worth trying, which will allow the productivity and work quality of pickers to improve. The aim of this study is to analyze the performance of a saffron separator for different air flows to increase the efficiency of post-harvest operations.

\section{Saffron flower parts separator details}

A prototype machine is utilized for experimentation in order to validate the proposed approach. This prototype machine design is based on saffron aerodynamic properties, which the main point of the proposed method consists of moving the saffron flowers parts by different aerodynamic behaviors of each element. The aerodynamic properties relate to terminal velocity of different parts of flower which are investigated (Emadi and Yarlagadda, 2008). Saffron parts (stigma, anther and petal) have diverse geometric shapes and weights, therefore, they have different aerodynamic properties and their aerodynamic resistances are significantly dissimilar. The terminal velocities range from 1.52 to $2.38(\mathrm{~m} / \mathrm{s})$ for the stigma and from 1.32 to $2.34 \mathrm{~m} / \mathrm{s}$ for the anther when the moisture content increases from 4 to $79 \%$ (w.b.\%) and 7.4 to $60 \%$, respectively (Emadi and Saiedirad 2011). The obtained range of terminal velocity for the petal was lower than that of the other two parts of the flower. Consequently, their behavior on the air flow stream is different and finally stigmas are clearly separated from the petals with an air flow. The structural design is based on different aerodynamic behaviors of saffron flower in the wind tunnel.

The design draft of the separator is presented in Figure 2. The prototypes include:

- Section A prevents the stigma to fall on the fan

- Outlet B is considered for outgoing stigma

- Outlet D are planned to leave the other parts of the flower

- Inlet $\mathrm{C}$ is designed to feed saffron flower parts to the machine

The dimension of outlets presented in the Table 1.

Table 1 Dimensions of the saffron separator

\begin{tabular}{l|l}
\hline Section & Rectangular size $(\mathrm{cm})$ \\
\hline Section A & $40.6 * 40.6$ \\
Outlet B & $40.6 * 33$ \\
Outlet D & $40.6 * 18$ \\
\hline
\end{tabular}


By using a flexible and changeable driver in outlet B and $\mathrm{D}$, it is possible to change air flow speed in each section independently (Figure 3). Therefore, they have high significant effect on the separation process.

Plexiglas is employed to build separator prototype since it is transparent so that the whole process can be observed. Because of static electricity all walls are covered with a layer of aluminum. The separator machine (Figure 4) which is designed and fabricated in the Agricultural Research Center of Mashhad (Iran) (Emadi and Yarlagadda, 2008) is utilized for this study.
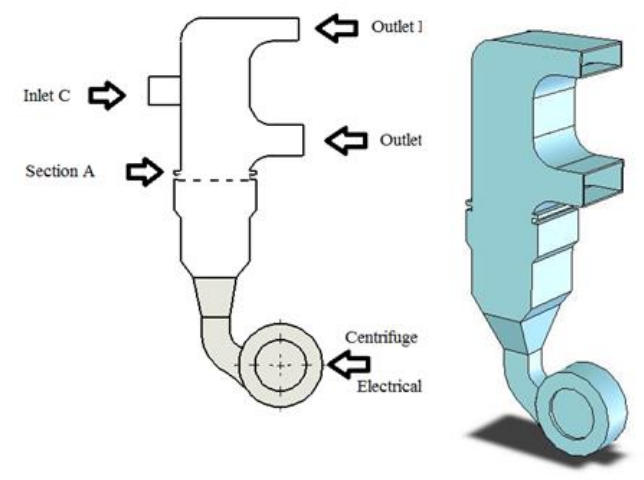

Figure 2 Schematic representation of the automated saffron separator, inlet and outlets of separator are shown

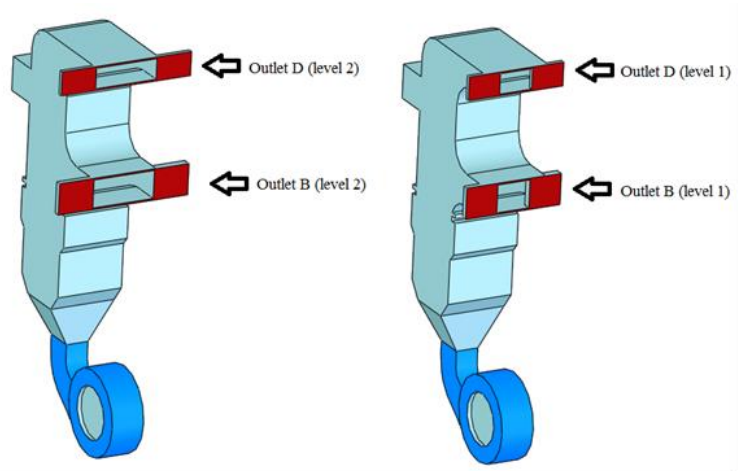

Figure 3 The position of drivers in the level 1 and level 2

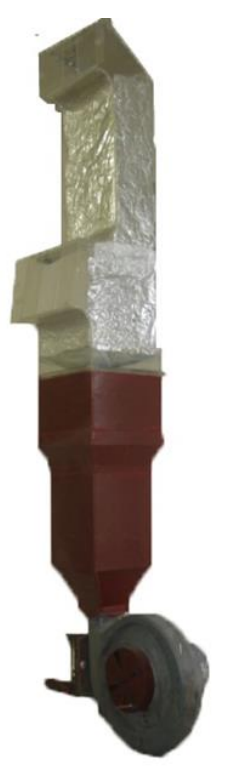

Figure 4 The model of saffron separation

\section{Materials and Methods}

Since the country of Iran produces more than 90 percent of the world's total production of saffron, and more than 92 percent of Iranian saffron is cultivated in Khorasan province with nearly 210 Tons Annual Production (Golmohammadi, 2014). The saffron flowers using for experiments are provided from farms around Kashmar region in Khorasan Razavi province, Iran. Flowers are taken directly to the lab in the shortest time span. The flowers are taken out daily from the store and each flower is cut from the receptacle point. A cutting mechanism is presented in the Figure 5. All the flowers are divided into several patches which contained 10 saffron flowers.

In order to determine the correlations between the saffron separator parameters and the operations results, a statistical methodology is considered based on the experimental design (DOE) which relates the input parameters to the response. These advanced Design of Experiments (DOE) capabilities improve to analyze processes and assist to determine which factors are influential to explain process variation and further understand how factors interact and drive the process. Subsequently, the factor settings which produce the optimal process performance are determined. The input parameters are air flow speed (3 levels), area of outlet B (2 levels) and outlet D (2 levels) (D and B driver placed in the two positions; semi open and completely open) and time of process ( 2 levels ( 30 and 60 seconds)), all details are shown in the Table 2. The number of saffron parts (stigma, anther and petal) which exit from outlet B, outlet $\mathrm{D}$ and remain in the section $\mathrm{A}$ are considering as the output parameters. Therefore, 24 experiments are carried out. Ten flowers are used in every run which 30 stigmas must be separated from the other parts ideally. Moreover, a portable air flow meter (Air Flow Meter PCE-007) which has the external impeller with the accuracy of $\pm 3 \%$ $\pm 0.1(\mathrm{~m} / \mathrm{s})$ and the resolution of $0.01 \mathrm{~m} / \mathrm{s}$ and $0.1 \mathrm{~m}^{3} / \mathrm{h}$ is used for measuring the air flow speed as shown in the Figure 6. The experiments are run to determine the actual effects of the four factors and investigated the significance of effecting; finally, this data will be applied to find the optimum areas of outlet $\mathrm{A}$ and $\mathrm{B}$, as two main parameters which have significant effect on the separator efficiency.

Table 2 Experimental levels for each parameter

\begin{tabular}{l|ll}
\hline Parameter & $\mathrm{L}$ & Parameter Quantify \\
\hline Air flow Speed & 3 & $\begin{array}{l}\text { Low level }(2 \mathrm{~m} / \mathrm{s}), \text { medium level } \\
(3 \mathrm{~m} / \mathrm{s}) \text { and high level }(4 \mathrm{~m} / \mathrm{s})\end{array}$ \\
Time & 2 & $\begin{array}{l}\text { level } 1=30 \text { second } \\
\text { level } 2=60 \text { second } \\
\text { Outlet area level 1 }=120 \mathrm{~mm}^{2} \\
\text { Outlet area level } 2=250 \mathrm{~mm}^{2}\end{array}$ \\
$\begin{array}{l}\text { The Area of } \\
\text { Outlet B }\end{array}$ & 2 & $\begin{array}{l}\text { Outlet area level } 1=120 \mathrm{~mm}^{2} \\
\text { Outlet area level } 2=250 \mathrm{~mm}^{2}\end{array}$ \\
\hline $\begin{array}{l}\text { The Area of } \\
\text { Outlet C }\end{array}$ & 2 & \\
\hline L: Level &
\end{tabular}

\section{Results and Discussions}

The aim of this prototype separator is to detach stigmas from the other parts of saffron. It is expected that 
stigmas leave from outlet $\mathrm{B}$ or remains in the section A. To analyze the data from the number of stigmas which exit from outlet $\mathrm{B}$ verified the influence of the processing parameters. According to the results of the ANOVA technique (Table3) $(\mathrm{P}<0.05)$, air flow speed, and area of outlet $\mathrm{B}$ have a significant role in the number of stigmas which leave from outlet B as presented in Figure 7. It is evident that the effect of processing time is not significant. The same data analyses for petal which exit from outlet D confirm that the area of outlet $\mathrm{D}$ has significant effect on the response (the number of petal exit from outlet D) as illustrated in Figure 8.

Table 3 Analysis of Variance for the Number of Separated Stigma, using Adjusted SS for Tests

\begin{tabular}{l|llllll}
\hline Source & DF & Seq SS & Adj SS & Adj MS & F & P \\
\hline Air flow speed & 2 & 404.08 & 404.08 & 202.04 & 11.97 & 0.001 \\
Time & 1 & 0.00 & 0.00 & 0.00 & 0.00 & 1.000 \\
& & & & & & \\
The Area of Outlet B & 1 & 266.67 & 266.67 & 266.67 & 15.79 & 0.001 \\
The Area of Outlet C & 1 & 170.67 & 170.67 & 170.67 & 10.11 & 0.005 \\
Error & 18 & 303.92 & 303.92 & 16.88 & & \\
Total & 23 & 1145.33 & & & & \\
\hline
\end{tabular}

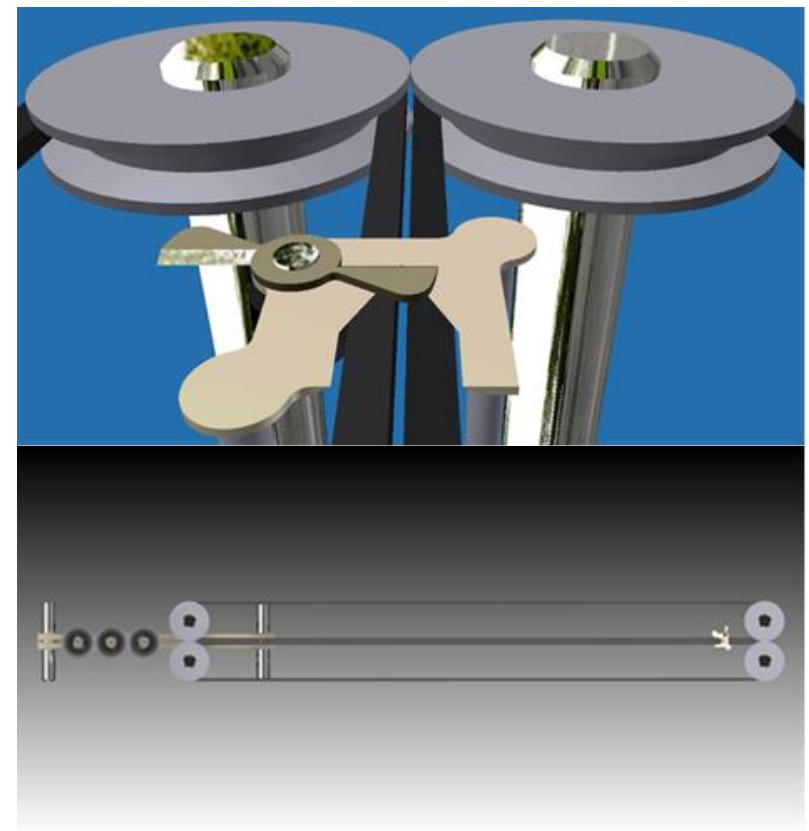

Figure 5 Cutting system

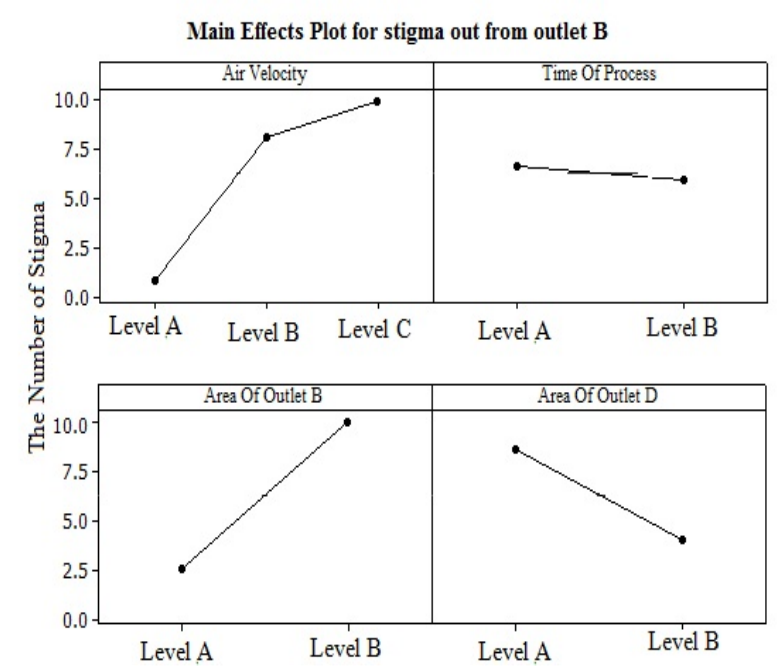

Figure 7 Main effects plot for the stigma that exit from outlet B

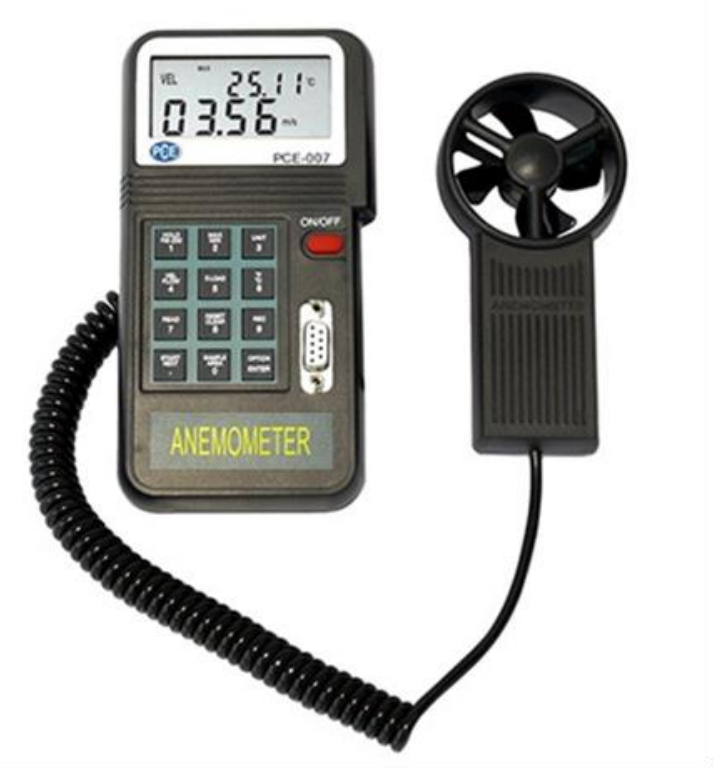

Figure 6 The air flow meter with external impeller

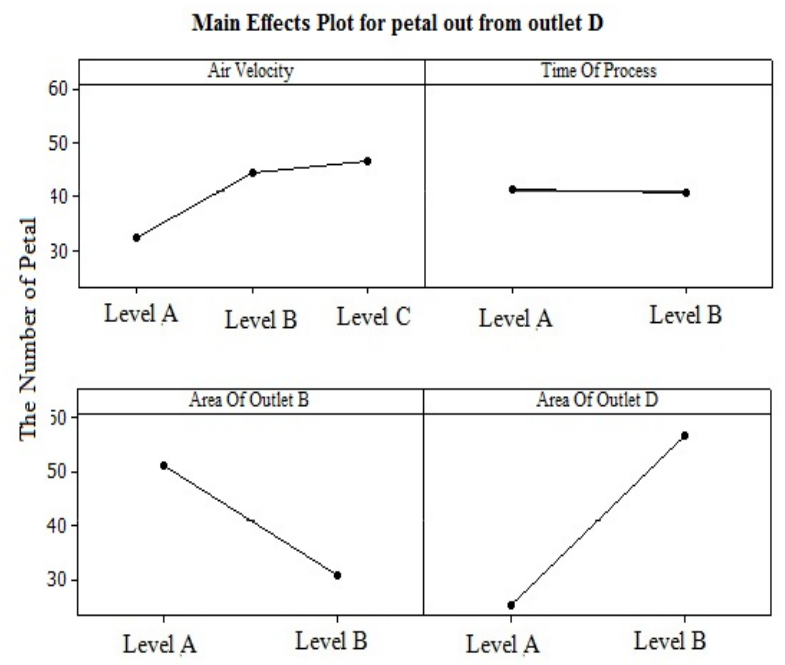

Figure 8 Main effects plot for the petal that exit from outlet D 


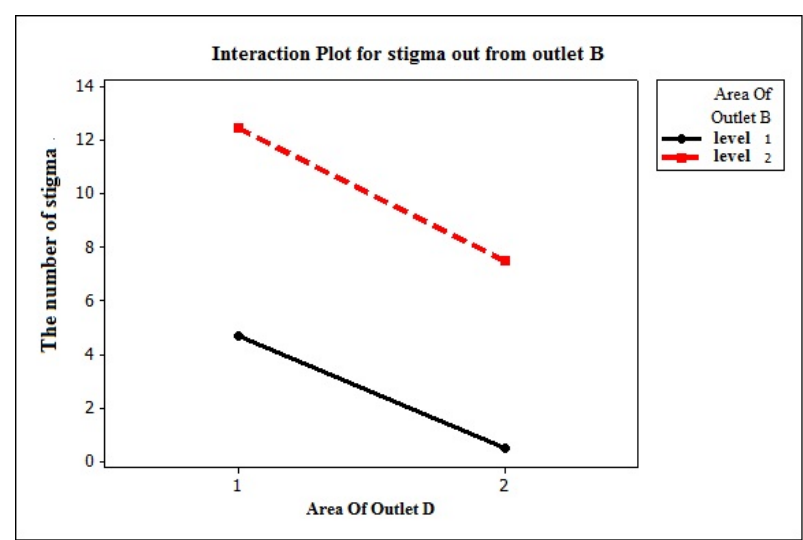

Figure 9 Interaction plot for the stigma that exit from outlet B

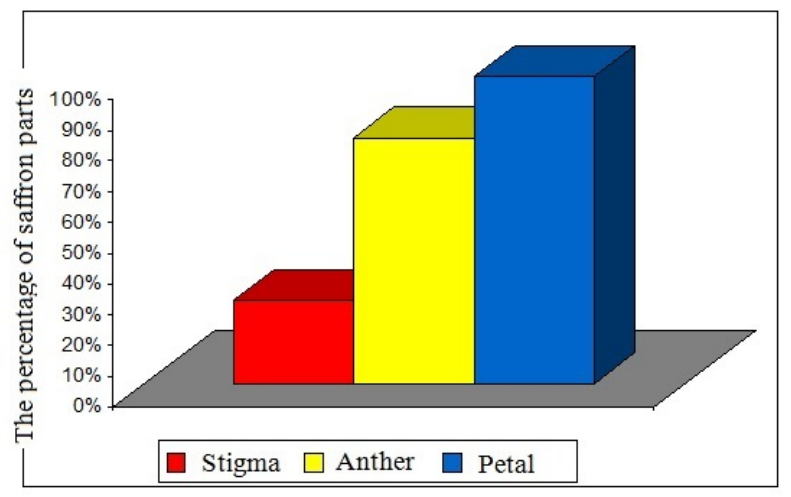

Figure 11 The percentage of petal that leave from outlet D

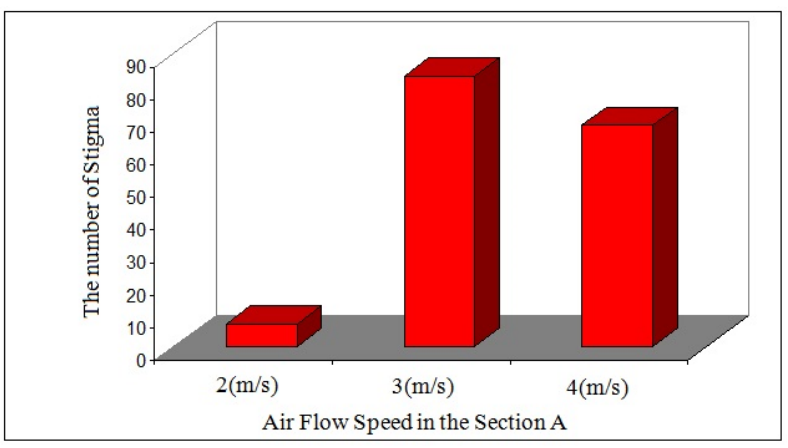

Figure 13 The relationship between the number of stigmas that exit from outlet $\mathrm{B}$ and air flow speed in section A (the maximum number of Stigma should be 240).

The interaction between the area of outlet B and D has significant effect on the number of stigmas and petals which leave outlet B and D respectively. The interaction effects are presented in the Figure 9 and 10; however, its effect is lower than the main effects.

This indicates that the output area has a significant impact on air flow speed. The best separation occurs at the 3-1-2-2 mode (air flow speed, outlet B and outlet D are high level and time of process is in the low level), that confirms that separator is design perfectly. At this mode, $100 \%$ of petals exit from the outlet D as represented in Figure 11; thus none of them remain at separator, and $63 \%$ of stigmas exit from the outlet B or remain in the section A as illustrated in Figure 12.

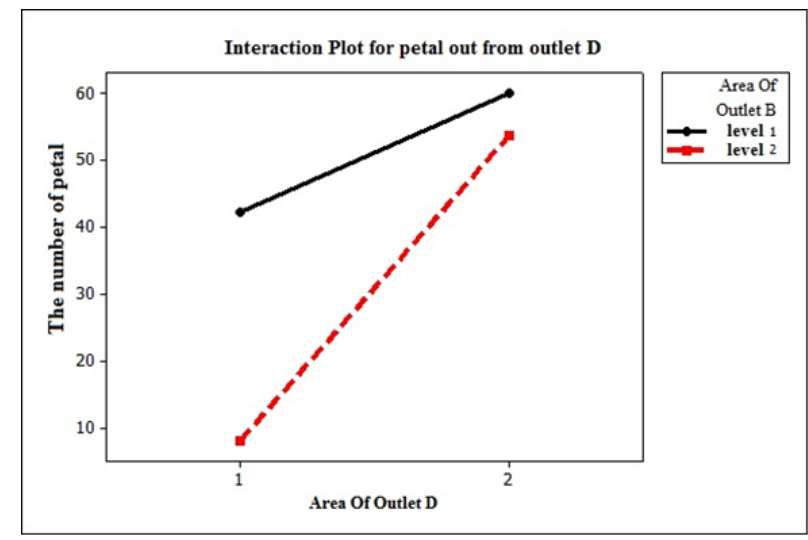

Figure 10 Interaction plot for the number of petals that exit from outlet D

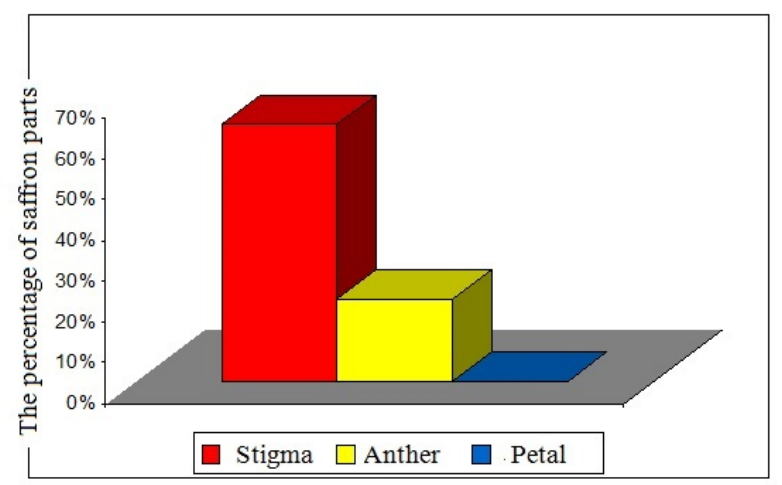

Figure 12 The percentage of Sigma that exit from outlet B or remain in the section $\mathrm{A}$

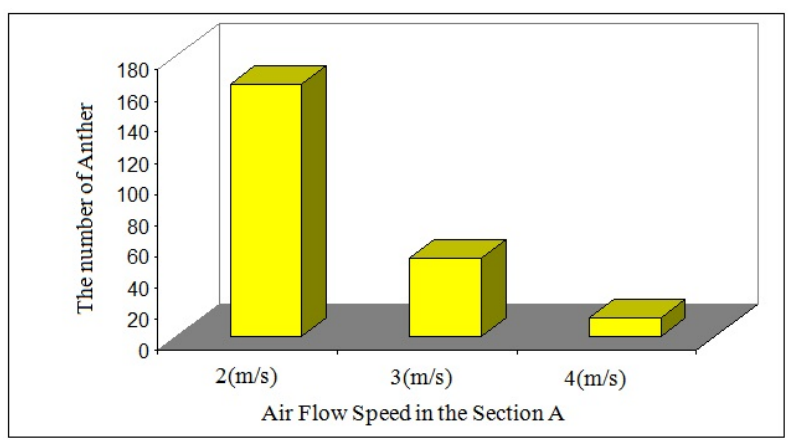

Figure 14 The relationship between the number of anthers that remain in the section $\mathrm{A}$ and air flow speed in section A (the maximum number of Anther should be 240).

The relationship between the air flow speed in the outlets and the number for stigmas, petals and anthers are also investigated. The number of stigmas which exit from the outlet B a with different air flow speeds in section A are demonstrated in Figure 13 and also the number of anthers which remain in the section $\mathrm{A}$ as presented in the figure 14 . The results show that the maximum number of stigma is separated in the air flow speed $3(\mathrm{~m} / \mathrm{s})$ and anther in $2(\mathrm{~m} / \mathrm{s})$. Meanwhile, other researchers show that the terminal velocities for stigma range from 2.4 to $2.8(\mathrm{~m} / \mathrm{s})$ and for the anther from 1.32 to $2.34(\mathrm{~m} / \mathrm{s}$ ) (Emadi and Yarlagadda, 2008); (Paschino and Gambella, 2008); (Emadi, 2009). 


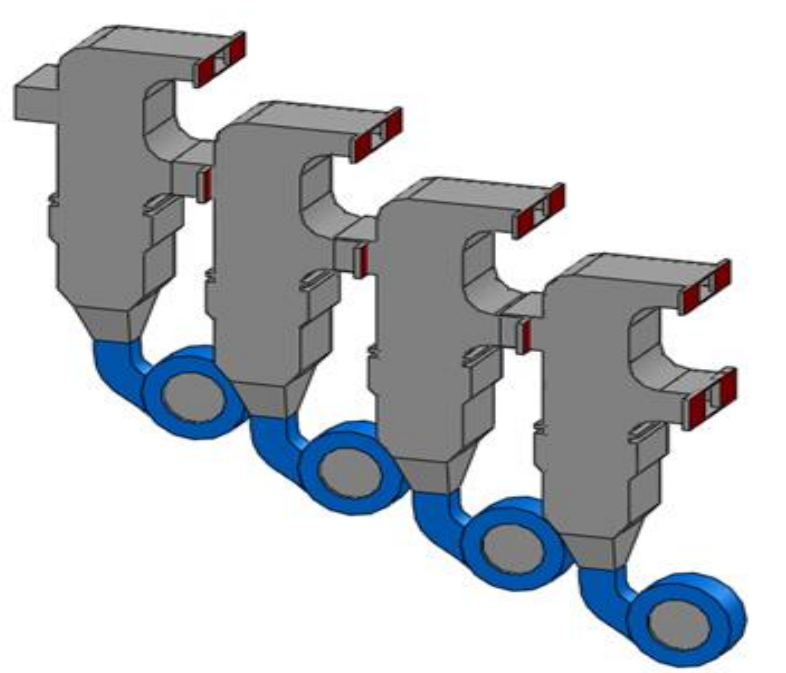

Figure 15 A mechanism for reprocess separation for increasing efficiency

The investigation results of the air flow speed measurement of three main parts of the flower in the outlets revealed that separation stigmas from the other parts of flower occur in any level of the air flow speed but with a different value of separation efficiency, because all saffron flowers and their parts are not completely similar to one another (their geometric figure, weight and moisture are diverse), their aerodynamic behaviors will be different and their stigmas or petals exit from the outlet in different air flow speeds.

It is demonstrated that is not possible to determine a terminal velocity with high accuracy to separate the saffron flower parts. Therefore, a machine designer must consider this phenomenon and using the flexible outlet areas or different air flow speeds will be suitable. Meanwhile reprocessing is an effective method to increase the efficiency of separation. Therefore, a multiseparator is suggested as presented in Figure 15. The outlet $\mathrm{B}$ is connected to the inlet $\mathrm{C}$; subsequently, stigmas, anthers and petals which exit from the outlet B are separated several times. Thus it increases the efficiency of separation process.

\section{Conclusions}

In this research, a separator is designed and manufactured on the basis of aerodynamic and physical properties of saffron flowers to separate stigma from other flower parts, and analyses the performance of this separator with different air flows shows that:

- The maximum stigma separation happens when the air flow speed in outlet B is $3(\mathrm{~m} / \mathrm{s})$.

- The investigation results on air flow speed measurement of outlets and the value of three main parts of the flower separation revealed that separating stigma from the other parts of flower occurs in any different air flow speeds in the outlets but with different efficiency, and the outlet areas have significant effect on the separation.

- It is suggested that using multi-separator with different air flow speeds would be increase the efficiency of separation.

\section{References}

Abdullaev FI. 2004. Biomedical properties of saffron and its potential use in cancer therapy and chemoprevention trials. Cancer Det. Preven., 28: 426-432.

Aydin C. 2002. Physical properties of hazel nuts. Biosystems Engineering., 82: 297- 303.

Bertetto AM, Falchi C, Pinna R, Ricciu R. 2010. An integrated device for saffron flowers detaching and harvesting, 19th International Workshop on Robotics in Alpe-Adria-Danube Region - RAAD. Budapest, Hungary. 24-26 June 2010. IEEE, PP: $93-98$.

Castillo R, Fernandez JA, Gomez-Gomez L. 2005. Implications of carotenoid biosynthetic genes in apocarotenoid formation during the stigma development of Crocus sativus and its closer relatives. Plant Physiology., 139: 674-689.

Demir F, Akinci I. 2004. Physical and nutritional properties of four major commercial Turkish hazelnut varieties. Journal of Food Engineering., 63: 341-347.

Emadi B. 2009. Separating saffron flower parts using vertical air column. World Academy of Science, Engineering and Technology., 49: 25-28.

Emadi B, Saiedirad MH. 2011. Moisture-dependent physical properties of saffron flower. Journal of Agricultural Science and Technology, 13: 387-398.

Emadi B, Yarlagadda PKDV. 2008. Design of a wind tunnel for separating flower parts of saffron. Journal of Achievements in Materials and Manufacturing Engineering., 31: 635-638.

Golmohammadi F. 2014. Saffron and its Farming, Economic Importance, Export, Medicinal characteristics and Various Uses in South Khorasan Province-East of Iran. International Journal of Farming and Allied Sciences., 3: 566-596.

Gracia L, Perez-Vidal C, Gracia-Lopez C. 2009. Automated cutting system to obtain the stigmas of the saffron Flower, Biosystems Engineering., 104: 8-17.

Hassan-Beygi S, Vale H, Khazaei, J. 2010. Picking force of saffron flower and shear strength of saffron stalk. Electronic Journal of Polish Agricultural Universities, 13:1-9.

Kafi M, Rashed MH, Koocheki A, Mollafilabi A. 2002. Saffron Production Technology and Processing. Center of Excellence for Agronomy (Special Crops). Faculty of Agriculture, Ferdowsi University of Mashhad, Iran, 37: 53-57.

McGimpsey JA, Douglas MH, Wallace A.R. 1997. Evaluation of saffron (Crocus sativus L.) production in New Zealand. NewZealand Joumal of Crop and Horticultural Science., 25: 159-168.

Mohammad HSR. 2006. Design and development of a two-raw saffron bulb planter. Agricultural Mechanization in Asia, Africa and Latin America, 37: 48-50.

Mohsenin NN. 1986. Physical Properties of Plant and Animal Materials, Structure, Physical Characteristics and Mechanical Properties, $2^{\text {nd }}$ updated and revised edition Gordon and Breach Science Publisher, New York, 241.

Negbi M. 1999. Saffron. Crocus sativus L. Harwood Academic Publ. I Overseas Publ. Ass., Amsterdam.

Ozguven F, Vursavus K. 2005. Some physical, mechanical and aerodynamic properties of pine (Pinus pinea) nuts. Journal of Food Engineering., 68: 191-196.

Paschino F, Gambella F. 2008. First contribute to the mechanization string of saffron flowers (Croccus Sativus L), International Conference of Innovation Technology to Empower Safety, Health and Welfare in Agriculture and Agro-food Systems. Ragusa - Italy. September 15-17, 2008.

Premkumar K, Thirunavukkarasu C, Abraham SK, Santhiya ST, Ramesh A. 2006. Protective effect of saffron (Crocus sativus L.) aqueous extract against genetic damage induced by antitumor agents in mice. Human and Experimental Toxicology. 25: 79-84.

Ruggiu M, Bertetto AM. 2006. A mechanical device for harvesting crocus sativus (saffron) flowers. Applied Engineering in Agriculture. 22: 491-498. 